\title{
Product MARKeT INTEGRATION AND INCOME TAXATION: DisTORTIONS AND GAINS FROM TRADE
}

\author{
TORBEN M. ANDERSEN \\ ALLAN SøRENSEN
}

CESIFO WORKING PAPER NO. 2170

CATEgory 1: Public FinANCE

DECEMBER 2007

Presented at CESifo Area Conference on Public Sector ECONOMics, APRIL 2007

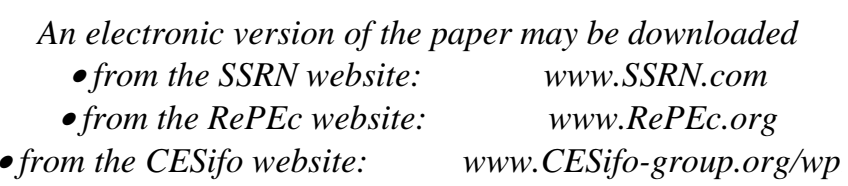




\title{
PRODUCT MARKET INTEGRATION AND INCOME TAXATION: DISTORTIONS AND GAINS FROM TRADE
}

\begin{abstract}
It is widely perceived that globalization is a threat to tax financed public sector activities. The argument is that public activities (public consumption and transfers) financed by income taxes may distort labour markets and cause higher wages and thus a loss of competitiveness. If the importance of the latter effect is reinforced by globalization, it is inferred that the marginal costs of public funds increase and a retrenchment of the public sector follows. We consider this issue in a Ricardian trade model in which production and specialization structures are endogenous. Even though income taxation unambiguously worsens wage competitiveness, it does not follow that tax distortions or marginal costs of public funds increase with product market integration. The reason is that gains from trade tend to reduce both. Moreover, noncooperative fiscal policies do not have a bias towards retrenchment due to a positive terms of trade effect from taxation.
\end{abstract}

JEL Code: H2, F1, J22.

Keywords: labour taxation, open economy, policy spill-over, marginal costs of public funds.

Torben M. Andersen

School of Economics and Management

Aarhus University

8000 Aarhus C

Denmark

tandersen@econ.au.dk
Allan Sørensen

School of Economics and Management

Aarhus University

8000 Aarhus C

Denmark

asoerensen@econ.au.dk

December 2007

Comments and suggestions given to previous versions of this paper at presentations at the CESifo conference Public Sector Economics, the Third Danish International Economics Workshop, and seminars at EPRU and Cambridge are gratefully acknowledged. 


\section{Introduction}

Is globalization a threat to an extended welfare state relying on a large public sector and therefore high tax burdens? Popular debates are widely based on the premise that the answer is affirmative, and in policy debates the pressure for retrenchment is often highlighted. Despite this strong perception, it is an empirical fact that when globalization is measured by the trade share, one finds a tendency that more globalized economies have larger public sectors (see e.g. Rodrik (1998)).

The debate on the globalization threat to the public sector focuses on two issues pertaining to tax financing of public sector activities. One mechanism is increased factor mobility forcing tax reductions on the mobile factors and thus causing a revenue drag $^{1}$. This can be interpreted as a direct threat to the public sector in the sense that the market enforces a change in policies (see e.g. Tanzi (2000) and Razin and Sadka (2005)). However, it is a fact that the larger share of tax revenue accrues from direct and indirect taxation of labour income, and since labour mobility has not seemed to increase significantly ${ }^{2}$, it follows that the direct revenue effects are moderate. This does not preclude that there are effects on the tax system since the tax structure would have to be adapted to this situation ${ }^{3}$, but it suggests that this mechanism is not causing a fundamental threat to a tax financed public sector. An important issue is whether globalization increases tax distortions in labour markets. Thus, if that is the case, tax financing may remain feasible, but it will become more costly and hence less attractive (for given policy preferences). A key tax distortion arises through the effect taxation may have on labour supply and thus wage competitiveness, which in turn has implications for production and employment (see e.g. Alesina and Perotti (1997)). This channel of tax distortions may have been strengthened because globalization makes it easier to relocate production and thus employment across countries. In short, globalization may increase the tax distortions and thus the marginal costs of public funds.

Most discussions of these issues are based on partial equilibrium reasoning. However, this is potentially misleading since the general equilibrium effects of market integration are very important, and it is from these that the aggregate gains from international integration derive. This is very important in the present context since gains from international integration are reflected in higher income, consumption etc., which in turn can have important implications for both the distortionary effects of taxation and the optimal level of public activities. In this paper, we show that common perceptions on how fiscal policy affects wage competitiveness are supported by the general equilibrium analysis. However, the inference often made in terms of implications for tax

\footnotetext{
${ }^{1}$ For evidence on such downward competitiveness on taxes, see e.g. EAAG (2007)

${ }^{2}$ A significant increase in migration coupled with selection mechanisms resulting in net-inflow of less skilled and net-outflow of highly skilled will obviously be a serious threat to a tax financed welfare model.

${ }^{3}$ The so-called dual income taxation scheme adopted in the Scandinavian countries, which allows a separation of taxation of labour income and capital income, makes it possible to combine a high and progressive labour income taxation with a low and proportional taxation of capital income.
} 
distortions, marginal costs of public funds and the direction in which policies will be changed as a result of product market integration are not. The basic reason is that the effects running via competitiveness are countered by effects which basically originate from the fact that integration leads to gains from trade. Hence, the very basic argument for further integration has important and surprising implications for fiscal policy responses.

We consider a general equilibrium setting allowing for an endogenous determination of production, specialization and thus trade structure across countries. Product market integration is modelled as reductions in trade frictions, which in turn imply that the non-tradeable sector shrinks and that there is reallocation of production and employment according to comparative advantages and thus gains from specialization. The public sector finances public consumption (service provision) and transfers via an income tax. In this general equilibrium setting, we analyse how fiscal policy affects various key variables including wage competitiveness, and we consider the optimal determination of both transfers and public consumption. We discuss how the effects of fiscal policy and the optimal policy response (for given policy objectives) change in the wake of further international integration. One pertinent question is: Does globalization necessarily lead to a retrenchment of public sector activities? We also address whether the "competitiveness effect" causes countries acting non-cooperatively to chose a too low level of public sector activities relative to the cooperative case to attain a competitive edge; i.e. is there a "race to the bottom" mechanism? It turns out that neither of the answers are affirmative.

The present paper merges elements from trade theory, macroeconomics and public economics. Ricardian models have recently been widely used to analyse the effects of international integration since this framework allows for an endogenous determination of production, trade and specialization structure depending on trade frictions as a metric of market integration. Since globalization driven by both political and technological changes lowers trade frictions, it follows that this framework captures essential elements of the changes and effects associated with the globalization process. This literature builds on Dornbusch, Fischer and Samuelson (1977), and recent contributions include e.g. Helpman, Melitz and Yeaple (2004), Eaton and Kortum (2002), Bernard et al. (2003), and Bernard, Jensen and Schott (2004).

The issue of fiscal policy in open economies has been extensively studied both in the macroeconomic and public economics literature. Most closely related to the present paper is the literature addressing international interdependencies in fiscal policy in explicitly formulated general equilibrium models. The standard set-up has featured specialized production; that is, countries specialize in production of specific commodities. The production structure is exogenous, and hence although there is trade, the trade and specialization structure is invariant to both policy changes and integration. One surprising but robust finding in these models is that fiscal policies tend to be too expansionary when comparing the non-cooperative to the cooperative policy outcome (see e.g. Chari and Kehoe (1990), Devereux (1991), Turnovsky (1988) and van der Ploeg (1987, 1988)). 
The reason is a terms-of-trade or "beggar thy neighbour" effect. Fiscal policy in the form of demand for domestically produced goods tends to shift demand from foreign to domestic products (home-bias), which in turn is perceived to improve the terms of trade and thus the real income of the home country. No such terms-of-trade effect arises in the (symmetric) cooperative case, and therefore non-cooperative policies tend to be too expansionary ${ }^{4}$. This result holds also in the presence of distortions, implying an inefficiently low level of activity and therefore a potential role for fiscal policy in expanding activity and employment (Andersen, Rasmussen and Sørensen (1996)). As noted, this literature relies on a home-bias in public consumption and an exogenous production/specialization structure. Relaxing both assumptions, our model supports the result that a terms-of-trade effect implies an expansionary bias in non-cooperative fiscal policy ${ }^{5}$.

The paper is organized as follows: The basic structure of the Ricardian trade model with trade frictions and a public sector is laid out in section 2, and section 3 characterizes the general equilibrium to the model. Effects of fiscal policy changes and tax distortions are analysed in section 4, while section 5 considers the case of transfers only and the marginal costs of public funds. Section 6 analyses the optimal level of public consumption (service provision), and section 7 offers some concluding remarks.

\section{A two-country model}

We set up a two-country model. Both countries finance public consumption and transfers by a proportional income tax. Given trade frictions and comparative advantages, the trade and specialization structures are endogenously determined. Production factors are perfectly mobile within countries but cannot move across borders.

\section{Households}

The representative household derives utility from private $(B)$ and public $(G)$ utility bundles

$$
U(B, G)
$$

The private utility bundle consists of private consumption $C$ and leisure $1-L$ (time endowment minus work), i.e. ${ }^{6}$

$$
B \equiv C+V(1-L)
$$

The public utility bundle consists of services provided by the public sector to all households. The

\footnotetext{
${ }^{4}$ Irrespective of whether the policy in absolute terms is expansionary or contractionary.

${ }^{5}$ In Andersen (2007), a related framework is considered in which wage setting is modelled in such a way that public activities may have a direct effect to moderate wages for given employment; e.g. via day care facilities. In this setting, non-cooperative policies may have a downward bias.

${ }^{6} \mathrm{~A}$ more general formulation is considered in appendix A.
} 
$U-, V-$ and $H$-functions are all increasing and concave. ${ }^{7}$

The utility from private consumption is defined by an indirect utility function (homothetic preferences $^{8}$ )

$$
C=\phi(\mathbf{Q}) I
$$

where $\mathbf{Q}$ denotes the price vector for the continuum of goods indexed by $i \in[0,1]$, and $I$ denotes disposable income.

Households own the firms and therefore receive profit income in addition to their labour income. A proportional tax $t$ is levied on all forms of income. Disposable income $I$ is thus given as

$$
I=[1-t][W L+\Pi]+T R
$$

where $W$ denotes the wage rate, $\Pi$ profits and $T R$ lump-sum transfers from the public sector.

A key property of homothetic preferences is that expenditure shares are independent of income and therefore depend only on prices $\mathbf{Q}$. In fact, the expenditure shares are homogenous of degree zero in the price vector. Denoting consumption of commodity $i$ by $C_{i}$, we have that the expenditure share $e_{i}$ for commodity $i$ is given by

$$
e_{i}(\mathbf{Q}) \equiv \frac{Q_{i} C_{i}}{I}
$$

We assume that expenditure shares are differentiable in the price vector $\mathbf{Q}$.

Labour supply is determined from the first order condition

$$
\phi(\mathbf{Q}) W[1-t]=V^{\prime}\left(1-L^{s}\right)
$$

implying that labour supply can be written ${ }^{9}$

$$
L^{s}=S(\phi(\mathbf{Q}) W[1-t]), \quad \frac{\partial S}{\partial \phi(\mathbf{Q}) W[1-t]}>0
$$

The household structure in the foreign country is similar - with all variables indexed by $*$ to denote that they apply to the foreign country.

\section{Producers}

Product markets have perfect competition, and firms produce subject to constant returns to scale production functions with labour as the only input $\left(Y_{i}=A_{i} L_{i}\right)$, cf. the standard Ricardian trade model. ${ }^{10}$ Commodity specific productivities differ across countries. For each good $i$, let $A_{i}$ and $A_{i}^{*}$ denote domestic and foreign productivity in producing commodity $i$, respectively, and let

\footnotetext{
${ }^{7}$ We further assume that $\lim _{L \rightarrow 1} V_{1-L}^{\prime}(1-L)=\infty, \lim _{L \rightarrow 0} V_{1-L}^{\prime}(1-L)=0$ and $\lim _{G \rightarrow 0} U_{G}(B, G)=\infty$ to avoid corner solutions.

${ }^{8}$ The properties of the indirect utility function (see e.g. Varian(1978)) include that: i) $\phi$ is homogenous of degree -1 in $\mathbf{Q}$, ii) $C$ is homogeneous of degree zero in $\mathbf{Q}$ and $I$, and iii) $\phi$ is decreasing in $\mathbf{Q}$.

${ }^{9}$ The quasi-linear preference relation implies that there is no income effect in labour supply.

${ }^{10}$ See e.g. Dornbusch, Fischer and Samuelson (1977)
} 
$a_{i} \equiv \frac{A_{i}}{A_{i}^{*}}$ be relative productivity. Assume without loss of generality that commodities are ordered such that $a_{i}$ is increasing in $i$. The main interest in the paper is to explore how public sector activities affect the equilibrium and how this interacts with product market integration. To avoid mixing this up with other possible effects and sources of asymmetries, we impose the following assumption:

Assumption 1: Relative productivity is symmetrically distributed ${ }^{11}$ around one, i.e. $a_{i}=a_{1-i}^{-1}$.

\section{Trade and prices}

Trade involves various frictions in the form of explicit or implicit trade costs (Samuelson's iceberg $\left.\operatorname{costs}^{12}\right)$. In order to deliver one unit of commodity $i$ on the export market $z(m) \geq 1, z_{m}<$ 0 , units have to be shipped off; i.e. $z$ captures a friction in international trade of commodities. Trade frictions are assumed to be symmetric with respect to the direction of trade. We use $m$ as an indicator of market integration reducing the impediment $(z)$ to trade. An increase in $m$ thus captures further product market integration. Note that nobody - at home or foreign - attains any income from the friction.

Prices charged by domestic and foreign firms are ${ }^{13}$

\begin{tabular}{|l|c|c|}
\hline & Domestic market & Foreign market \\
\hline Domestic firms & $\frac{W}{A_{i}}$ & $\frac{z W}{A_{i}}$ \\
\hline Foreign firms & $\frac{z W^{*}}{A_{i}^{*}}$ & $\frac{W^{*}}{A_{i}^{*}}$ \\
\hline
\end{tabular}

For any commodity $i$, consumers choose the supplier - domestic or foreign - with the lowest price $\left(\min \left[\frac{W}{A_{i}}, \frac{z W^{*}}{A_{i}^{*}}\right]\right)$, and given constant marginal costs, the winner takes all. The critical condition determining which firm supplies the market is thus $\frac{W}{A_{i}} \lesseqgtr \frac{z W^{*}}{A_{i}^{*}}$ or $w \lesseqgtr a_{i} z$, where $w=\frac{W}{W^{*}}$ denotes the relative wage. Since relative productivity $a_{i}$ increases in $i$, there exists a critical value of $i$ $\left(i^{H}\right)$ defined by $w \equiv z a_{i^{H}}$ with the property that for all $i \geq i^{H}$, good $i$ is produced domestically. ${ }^{14}$ Similarly, there is a critical value of $i\left(i^{E}>i^{H}\right)$ defined by $w \equiv z^{-1} a_{i^{E}}$ with the property that for all $i>i^{E}$, good $i$ is only produced domestically and exported to the foreign market. Hence, goods $i<i^{H}$ are imported, $i^{H} \leq i \leq i^{E}$ are non-tradeables, and $i>i^{E}$ are exportables. Figure 1 below summarizes.

\footnotetext{
${ }^{11}$ To ensure differentiability, we assume that the distribution has no mass points.

${ }^{12}$ Modelling trade frictions as Iceberg trade frictions simplifies the model as we avoid including a transport sector.

${ }^{13}$ The prices follow from the assumption of competitive firms producing with constant returns to scale production functions with labour as the only input.

Due to trade frictions, domestic (foreign) consumers have no incentive to buy goods in the foreign (domestic) market.

${ }^{14}$ This implies that for all $i<i^{H}$, good $i$ is only produced by foreign firms.
} 


\section{Figure 1: Trade and specialization structure}

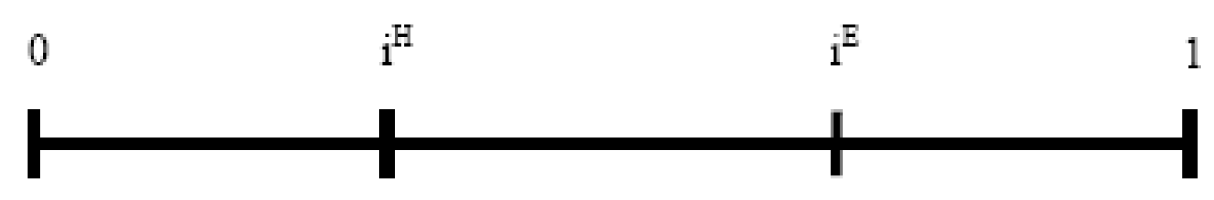

\section{Importables Non-tradeables Exportables}

We have that ${ }^{15}$

$$
\begin{array}{lll}
i^{E}=i^{E}(w, m) & \frac{\partial i^{E}}{\partial w}>0 & \frac{\partial i^{E}}{\partial m}<0 \\
i^{H}=i^{H}(w, m) & \frac{\partial i^{H}}{\partial w}>0 & \frac{\partial i^{H}}{\partial m}>0
\end{array}
$$

Higher relative wages imply higher $i^{E}$ and $i^{H}$, that is, domestic firms both produce and export fewer types of goods. The intuition is straightforward since it derives from the worsening of wage competitiveness. The more integrated the markets (higher $m$ and thus lower $z$ ), the higher $i^{H}$ and the lower $i^{E}$; i.e. with lower trade frictions, fewer goods are produced domestically, but more goods are exported. In other words, the number of non-tradeable goods decreases. Hence, changes in both wage competitiveness (endogenous) and the trade friction (exogenous) cause a change in the trade and specialization structure.

\section{Government}

The government may provide lump-sum transfers $(T R)$ and public services $(G)$ to households. Public services are produced by use of labour $\left(L^{g}\right)$, and it is assumed ${ }^{16}$ that $G=L^{g}$ (productivity is constant and for simplicity normalized to one). These activities are financed by a proportional tax levied on income ${ }^{17}$ by the rate $t$, and hence the budget constraint reads

$$
t[W L+\Pi]=W L^{g}+T R
$$

where $L$ is total employment, i.e. $L \equiv L^{p}+L^{g}$, where $L^{p}\left(L^{g}\right)$ denotes labour used in the private (public) sector.

To allow for a flexible way of capturing that the government may have different priorities between its two main activities (transfers and service provision), we denote by $\xi \in[0,1]$ the fraction of the tax revenue spent on lump-sum transfers to individuals, and the other part is used for public service provision. For $\xi=1$ we have a pure tax-transfer scheme without any aggregate demand effects, but only a supply side effect via the way the tax rate affects labour supply. This

\footnotetext{
${ }^{15}$ Trade can only occur in equilibrium if $a_{1}>z(m)$. As we are interested in open economy equilibria, we assume this condition to be fulfilled.

${ }^{16}$ The assumption implies that public activities are directed towards a non-tradeable, namely labour. Notice that the assumption here to a first approximation capture the fact that about $2 / 3$ of public consumption expenditures are wage expenditures.

${ }^{17}$ Observe that there is no profit in equilibrium due to competitive product markets, and there is no issue as to whether labour and profit income should be taxed at different rates.
} 
special case allows an identification of the pure distortion effect without mixing it up with other effects of public sector activities.

Using the public sector budget constraint and the fact that profits are zero in equilibrium allows us to write disposable income as

$$
I=[1-t] W L+\Pi+T R=W L^{p}
$$

i.e. disposable income is determined by the income generated in the private sector ${ }^{18}$. Using that profits are zero, it also follows from the public budget constraint (7) that

$$
L^{g}=\frac{[1-\xi] t}{1-[1-\xi] t} L^{p}
$$

\section{Equilibrium wages and gains from trade}

Although the model features many aspects, a considerable simplification is achieved by the fact that all endogenous variables can be written as functions of the relative wage $w$, and we can characterize the general equilibrium by the labour market equilibrium condition, which turns out to be equivalent to the balanced trade condition. Details are given in Appendix B. For the following, it is important to note that the real wage can be written $W \phi(\mathbf{Q})=\phi\left(\frac{1}{W} \mathbf{Q}\right) \equiv \Phi(w, m)$, where the first part uses the homogeneity of the $\phi$-function, and the second part the relation between prices and wages (see Appendix B). The real wage increases in the relative wage $(w)$ and market integration $(m)$, i.e.

$$
\frac{\partial \Phi(w, m)}{\partial w}>0, \frac{\partial \Phi(w, m)}{\partial m}>0
$$

Let $\psi^{M}(w, m)$ be the import share, i.e. the fraction of income domestic households spend on foreign goods. Further integration leaves an ambiguous effect on the import share since import prices decrease while import volumes increase. We make the following assumption ${ }^{19}$ ensuring that import shares increase with integration (the empirically relevant case).

Assumption 2: The import shares $\psi^{M}(w, m)$ and $\psi^{* M}(w, m)$ increase with market integration $(m)$.

Lemma 1 The home (foreign) import share increases (decreases) in the relative wage $w$

\footnotetext{
${ }^{18}$ Note that gross domestic product as conventionally measured in national accounts is given as (measured from the factor side)

$$
G D P=W L^{p}+W L^{g}
$$

${ }^{19}$ In a formulation where preferences exhibit a constant elasticity of substitution between any two goods, a sufficient condition to ensure that Assumption 2 is true is that the elasticity of substitution exceeds one.
} 
Proof. From Appendix B, it follows that

$$
\begin{aligned}
\operatorname{sign} \frac{\partial \psi^{M}}{\partial w} & =\operatorname{sign} \frac{\partial \psi^{M}}{\partial m} \\
\operatorname{sign} \frac{\partial \psi^{* M}}{\partial w} & =\operatorname{sign}\left[-\frac{\partial \psi^{* M}}{\partial m}\right]
\end{aligned}
$$

Hence, it follows directly from Assumption 2 that $\psi^{M}(w, m)$ increases in $w$ and $\psi^{* M}(w, m)$ decreases in $w$.

Labour supply can in equilibrium be written $S([1-t] \Phi(w, m))$, and it follows that labour supplied to the private sector becomes $S^{p}(w, t, \xi, m) \equiv[1-[1-\xi] t] S(\Phi(w, m)[1-t])$, and public employment is $S^{g}(w, t, \xi, m) \equiv[1-\xi] t S(\Phi(w, m)[1-t])$. From the labour market equilibrium, we have

Proposition 2 Existence and uniqueness of the equilibrium. The equilibrium condition to the model can be written

$$
\begin{aligned}
\Omega\left(w, t, \xi, t^{*}, \xi^{*}, m\right) & =\psi^{M}(w, m) S^{p}(w, t, \xi, m) w-\psi^{* M}(w, m) S^{p *}\left(w, t^{*}, \xi^{*}, m\right) \\
& =0
\end{aligned}
$$

For $t<1$ and $t^{*}<1$ the equilibrium relative wage exists, and it is uniquely determined from (10) and can in implicit form be written as

$$
w=\omega\left(t, \xi, t^{*}, \xi^{*}, m\right)
$$

Proof. The equilibrium condition follows from Appendix B. Let $\underline{w}$ and $\bar{w}$ be defined by $i^{H}(\underline{w}, m)=0$ and $i^{E}(\bar{w}, m)=1$ where $\bar{w}>\underline{w}$ as $a_{1}>z$ by assumption. $\Omega$ is continuous in $w$. We have $\Omega\left(\underline{w}, t, \xi, t^{*}, \xi^{*}, m\right)=-\psi^{* M}(\underline{w}, m) S^{p *}\left(\underline{w}, t^{*}, \xi^{*}, m\right)<0$ and $\Omega\left(\bar{w}, t, \xi, t^{*}, \xi^{*}, m\right)$ $=\psi^{M}(\bar{w}, m) S^{p}(\bar{w}, t, \xi, m) \bar{w}>0$. Hence, there exist a $w \in(\underline{w}, \bar{w})$ such that $\Omega\left(w, t, \xi, t^{*}, \xi^{*}, m\right)=$ 0 . This proves existence. From Lemma 1, (4) and (9) it follows that $\Omega$ is strictly increasing in $w$, i.e. $\Omega_{w}>0$, which proves uniqueness.

\subsection{Symmetric countries - gains from trade}

As a prelude to the subsequent analysis, it is useful to note that lower trade frictions are associated with gains from trade. Considering the symmetric equilibrium where fiscal policies are the same in the two countries, i.e. $t=t^{*}$ and $\xi=\xi^{*}$ and thus $w=1$.

Proposition 3 In a symmetric equilibrium a reduction in trade frictions increases welfare for given fiscal policy $(t, \xi)$. 
Proof. Utility of the representative household is given by

$$
\Upsilon=U\left(\Phi(1, m) S^{p}(1, \xi, t, m)+V\left(1-\frac{S^{p}(1, \xi, t, m)}{1-[1-\xi] t}\right), \frac{[1-\xi] t}{1-[1-\xi] t} S^{p}(1, \xi, t, m)\right)
$$

Using (3) we have

$$
\begin{aligned}
\frac{\partial \Upsilon}{\partial m} & =U_{B}\left[\Phi_{m} S^{p}+\Phi S_{m}^{p}-V_{1-L} \frac{S_{m}^{p}}{1-[1-\xi] t}\right]+U_{G} \frac{[1-\xi] t}{1-[1-\xi] t} S_{m}^{p} \\
& =U_{B}\left[\Phi_{m} S^{p}+\Phi S_{m}^{p}\left[1-\frac{1-t}{1-[1-\xi] t}\right]\right]+U_{G} \frac{[1-\xi] t}{1-[1-\xi] t} S_{m}^{p}
\end{aligned}
$$

Note that $\Phi_{m}>0 \mathrm{cf}$. (9), $S_{m}^{p}>0 \mathrm{cf}$. (4) and (9) and $\frac{1-t}{1-[1-\xi] t} \in[0,1]$. Hence, it follows that $\frac{\partial \Upsilon}{\partial m}>0$.

The utility gain has two components: increasing private $(B)$ and public $(G)$ utility bundles. The former captures standard gains from trade. The latter arises because one of the gains from integration is higher employment, which in turn means higher tax revenue and therefore (under the balance budget constraint) more public sector activities. Alternatively, to maintain a given level of public services, there would be room for a tax reduction, which in turn would increase the private utility bundle further.

\section{$4 \quad$ Fiscal policy and competitiveness}

Much debate on the public sector focuses on how public sector activities affect the competitiveness of the economy. We have:

Proposition 4 An unilateral increase in the tax rate ( $t$ ) raises the relative wage (w) and thus deteriorates wage competitiveness.

Proof. To see this note that (10) implies

$$
\Omega_{w} \frac{\partial w}{\partial t}+\Omega_{t}=0
$$

and hence

$$
\frac{\partial w}{\partial t}=\frac{-\Omega_{t}}{\Omega_{w}}=\frac{-S_{t}^{p} w \psi^{M}}{\Omega_{w}}>0
$$

The sign follows from noting $S_{t}^{p}<0 \mathrm{cf}$. (4) and (8), $\Omega_{w}>0 \mathrm{cf}$. the proof of Proposition 2.

This confirms the common perception that an increase in the tax rate tends to increase relative wages, and thereby worsen wage competitiveness (see e.g. Alesina and Perotti (1997)). The increase in the relative wage causes a reduction in both the number of commodities exported and produced in the domestic country, i.e. $i^{E}$ and $i^{H}$ increase, cf. figure 1.

In popular debates, it is often asserted that it is not the absolute level of taxes (size of the public sector) but taxes relative to taxes in competing countries that matter. The intuition is that competition is a relative matter. It is an implication of the present model that 
Proposition 5 The relative wage is independent of the absolute level of taxes and the composition of public expenditures when countries are symmetric, i.e. $w$ is invariant to $t$ and $\xi$ if $t=t^{*}$ and $\xi=\xi^{*}$. However, the private sector employment level is falling in $t$ (for given $\xi$ ) and increasing in $\xi$ (for given $t$ ).

Proof. When countries are symmetric $w=1$. The effects on private sector employment follow from (4) and (8)

While the present setting supports that only the relative wage matters for competitiveness and trade/specialization structure, it does not support that only the relative tax matters. The reason is that two margins are affected by taxes: first, the margin between foreign and domestically produced goods, which is affected only by the relative wage, and second the margin between consumption and leisure. Hence, the standard closed economy distortions remain with symmetric public sector sizes/structures (see also Proposition 7, below) although neither the trade structure nor relative wages are affected by a symmetric change in the tax rate.

The relative wage and thus competitiveness is a poor indicator of the welfare and employment effects of given changes in exogenous variables. The reason is that e.g. employment is affected both by the change in relative wages but also directly by the underlying cause for a change in the relative wage.

Cross-country variations in the size and composition of the public sector activities are large. In policy debates, it is often taken for granted that a large public sector is tantamount to a worsening of the competitive position, and partial models confirm this. With the present framework, we can analyse two key asymmetries, namely, differences in size and composition of the public sector.

Proposition 6 Size: If $t>t^{*}$ and $\xi=\xi^{*}$, i.e. the domestic public sector is more extended than the foreign, but the relative composition (services and transfers) is the same, it follows that $w>1$

Proof. The relative wage is from (30) determined by the condition

$$
w \frac{\psi^{M}(w, m)}{\psi^{* M}(w, m)}=\frac{S^{p *}\left(w, \xi^{*}, t^{*}, m\right)}{S^{p}(w, \xi, t, m)}
$$

where $\frac{\partial\left[\frac{\psi^{M}(w, m)}{\psi^{* M}(w, m)}\right]}{\partial w}>0$ and $\frac{\psi^{M}(1, m)}{\psi^{* M}(1, m)}=1 \mathrm{cf}$. Appendix B. Further, we have that $\frac{\partial}{\partial w}\left[\frac{S^{p *}\left(w, \xi^{*}, t^{*}, m\right)}{S^{p}(w, \xi, t, m)}\right]<$ 0 cf. (4) and (9) and $\frac{S^{p *}\left(1, \xi, t^{*}, m\right)}{S^{p}(1, \xi, t, m)}>1$ cf. (4) and (8). It follows that $w>1$.

Intuitively a large domestic (relative to foreign) tax burden causes a lower domestic labour supply, and this tends to increase the relative wage. Notice that this implies that more goods are imported and less are exported (compared to the symmetric case), but whether the non-tradeable sector expands or shrinks is ambiguous, i.e. both $i^{E}$ and $i^{H}$,increase cf. figure 1 . Moreover, it is an implication that domestic production is more concentrated on the activities for which it has a 
strong comparative advantage. Note also that the relative price of exportables increase, i.e. there is a terms of trade effect muting the loss of production of some tradeables.

Turning to the composition, we have

Proposition 7 Composition: If $\xi>\xi^{*}$ and $t=t^{*}$, i.e. the domestic public sector is relatively more focused on transfers than on public services compared to foreign, but the size of the public sector is the same, it follows that $w<1$.

Proof. The relative wage is determined by the condition

$$
w \frac{\psi^{M}(w, m)}{\psi^{* M}(w, m)}=\frac{S^{p *}\left(w, \xi^{*}, t^{*}, m\right)}{S^{p}(w, \xi, t, m)}
$$

where $\frac{\partial\left[\frac{\psi^{M}(w, m)}{\psi^{* M}(w, m)}\right]}{\partial w}>0$ and $\frac{\psi^{M}(1, m)}{\psi^{* M}(1, m)}=1$, and $\frac{\partial}{\partial w}\left[\frac{S^{p *}\left(w, \xi^{*}, t^{*}, m\right)}{S^{p}(w, \xi, t, m)}\right]<0$ cf. above and $\frac{S^{p *}\left(1, \xi^{*}, t, m\right)}{S^{p}(1, \xi, t, m)}<1$ cf. (8). It follows that $w<1$.

When a country focuses more on transfers than on provision of public services, the labour requirement of the public sector is lower (compared to foreign). The lower public labour requirement increases labour supply for the private sector and thereby reduces the relative wage. Consequently, more goods are exported and fewer imported, i.e. $i^{E}$ and $i^{H}$ decrease cf. figure 1 . The effect on the size of the non-tradeables sector is ambiguous but the terms of trade deteriorate in this case. The proposition can be seen as stressing that the effects of public activities and taxes depend critically on what the tax revenue is spend on.

These propositions show that both size and composition of fiscal policy are important for competitiveness.

In the present setting, the root of the distortion is the tax wedge affecting the labour supply. A metric of the importance of tax distortions which is useful in later analyses is the difference between labour supply $(S)$ without and with taxation, i.e.

$$
\left.\widetilde{S} \equiv S\right|_{t=0}-\left.S\right|_{t>0}>0
$$

Define the labour supply elasticity wrt. after-tax real wage as

$$
\eta^{S} \equiv \frac{S_{\Phi[1-t]} \Phi[1-t]}{S}>0
$$

we have

Proposition 8 Tax distortions and integration: In symmetric equilibria, tax distortions are increasing in the tax rate, $\frac{\partial \widetilde{S}}{\partial t}>0$, and the effect of trade frictions on the marginal tax distortion is determined by

$$
\operatorname{sign} \frac{\partial}{\partial m} \frac{\partial \widetilde{S}}{\partial t}=\operatorname{sign}\left[\eta^{S}+\frac{S}{S_{\Phi(1-t)}} \frac{\partial \eta^{S}}{\partial \Phi[1-t]}\right]
$$


Proof. The tax distortion is in symmetric equilibria where $t=t^{*}$ and $w=1$ given by

$$
\widetilde{S} \equiv S(\Phi(1, m))-S(\Phi(1, m)[1-t])
$$

Hence,

$$
\frac{\partial \widetilde{S}}{\partial t}=S_{\Phi[1-t]} \Phi(1, m)>0
$$

Considering the effects of trade frictions, we have

$$
\frac{\partial}{\partial m} \frac{\partial \widetilde{S}}{\partial t}=S_{\Phi[1-t]} \Phi_{m}\left[1+\frac{\partial S_{\Phi[1-t]}}{\partial \Phi[1-t]} \frac{\Phi[1-t]}{S_{\Phi[1-t]}}\right]
$$

where $\Phi_{m} S_{\Phi(1-t)}>0$. From the definition of the labour supply elasticity, we have

$$
\begin{aligned}
\frac{\partial \eta^{S}}{\partial \Phi[1-t]} & =\frac{\left[\frac{\partial S_{\Phi[1-t]}}{\partial \Phi[1-t]} \Phi[1-t]+S_{\Phi[1-t]}\right] S-\left[S_{\Phi[1-t]}\right]^{2} \Phi[1-t]}{S^{2}} \\
& =\frac{S_{\Phi[1-t]}}{S}\left[\frac{\partial S_{\Phi[1-t]}}{\partial \Phi[1-t]} \frac{\Phi[1-t]}{S_{\Phi[1-t]}}+1-\frac{S_{\Phi[1-t]} \Phi[1-t]}{S}\right] \\
& =\frac{S_{\Phi[1-t]}}{S}\left[\frac{\partial S_{\Phi[1-t]}}{\partial \Phi[1-t]} \frac{\Phi[1-t]}{S_{\Phi[1-t]}}+1-\eta^{S}\right]
\end{aligned}
$$

Hence,

$$
\frac{\partial S_{\Phi[1-t]}}{\partial \Phi[1-t]} \frac{\Phi[1-t]}{S_{\Phi[1-t]}}+1=\frac{S}{S_{\Phi(1-t)}} \frac{\partial \eta^{S}}{\partial \Phi[1-t]}+\eta^{S}
$$

implying that

$$
\frac{\partial}{\partial m} \frac{\partial \widetilde{S}}{\partial t}=S_{\Phi[1-t]} \Phi_{m}\left[\eta^{S}+\frac{S}{S_{\Phi(1-t)}} \frac{\partial \eta^{S}}{\partial \Phi[1-t]}\right]
$$

The essence of this result is that there is a direct effect which unambiguously implies that marginal tax distortions increase with integration, and there is an ambiguously signed indirect effect. Consider first the direct effect captured by the first term on the RHS of (12). The higher the integration $(m)$, the larger the real wage before $\operatorname{tax}(\Phi), \Phi_{m}>0$, and therefore the larger the real wage reduction induced by a given tax rate. That is, the employment loss due to higher taxation (measured by the labour supply elasticity) is larger, and therefore this works in the direction of increasing marginal tax distortions with more integration. The indirect effect is more complicated since it relates to whether we, as a result of integration, move to a part of the labour supply relation which is more or less elastic. To see this, note that a lower trade friction increases the after-tax real wage, and therefore we move up the labour supply relation. If $\frac{\partial \eta^{S}}{\partial \Phi[1-t]}>0$, the labour supply function is more elastic at a higher wage rate which tends to make the tax increase more distortionary, and vice versa if it becomes less elastic, i.e. $\frac{\partial \eta^{S}}{\partial \Phi[1-t]}<0$. In the former case, the indirect effect goes in the same direction as the direct effect, and we have that more market integration unambiguously increase marginal tax distortions $\left(\frac{\partial}{\partial m} \frac{\partial \widetilde{S}}{\partial t}<0\right)$. 
In the case $\frac{\partial \eta^{S}}{\partial \Phi[1-t]}<0$, we have an ambiguity between the direct and the indirect effect. This ambiguity will always arise for some wage rate. To see this, notice that $\frac{\partial \eta^{S}}{\partial \Phi[1-t]}<0$ for a sufficiently high real wage ${ }^{20}$. To put it differently, for a sufficiently high wage rate, the labour supply relation becomes inelastic since there is an upper bound (time limit) to how much labour can be supplied. To sum up, it is not possible to conclude unambiguously on how product market integration affects marginal tax distortions.

Figure 2: Example: Non-monotone distortion effect of product market integration

Figure 2a: Labour supply

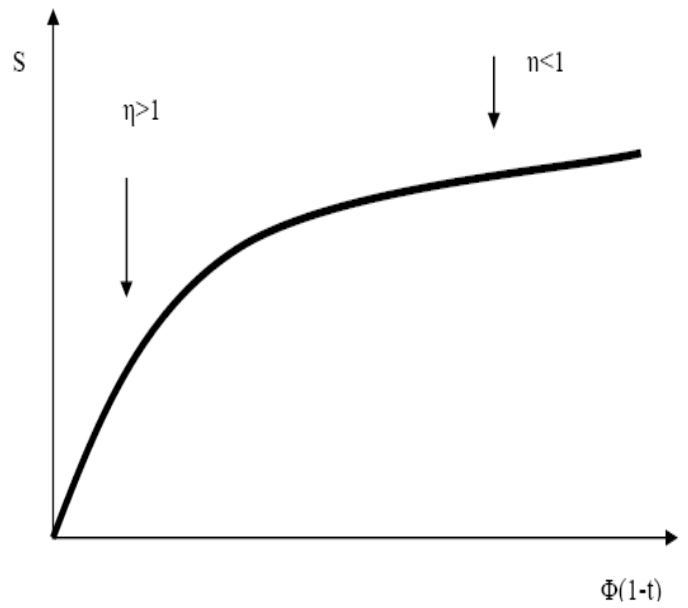

Figure 2b: Integration and tax distortions on employment

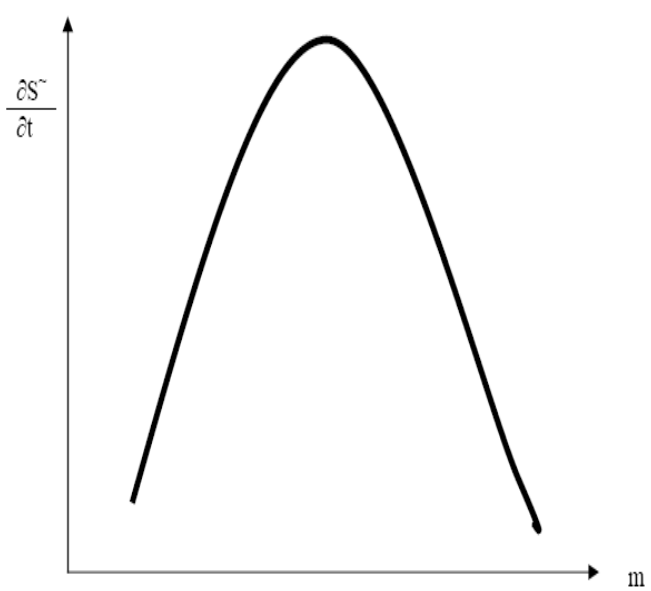

The result reported above suggests that the effect of integration on marginal tax distortions may not be monotone. Consider figure 2 where the labour supply elasticity is falling in the wage rate, i.e. $\frac{\partial \eta^{S}}{\partial \Phi[1-t]}<0$ for all $\Phi(1-t)$, and labour supply has an upward bound $(=1)$. In this case, it follows ${ }^{21}$ that the marginal distortion is hump-shaped in integration $(m)$; that is, at first more integration will increase marginal tax distortions, but when trade frictions are lowered to a certain level, marginal tax distortions will be falling with integration, cf. figure 2 .

\section{Optimal transfers and the marginal costs of public funds}

In the present set-up, the transfer part of public sector activities seems trivial as the representative household framework precludes any welfare gains from redistribution. Yet, restricting public sector activities to transfers $(\xi=1)$ is interesting since it highlights the distortionary effects of taxation without mixing them up with other effects of public sector activities.

When public sector revenue finances a transfer only $(\xi=1)$, there is no public employment, i.e. $S^{g}=0, S^{p}=S$. The problem of choosing the optimal tax rate $(t)$ under the constraint that

\footnotetext{
${ }^{20}$ We have $\eta^{S} \geq 0$. Since $L \rightarrow 1$ for $\Phi[1-t] \rightarrow \infty$, implying $V^{\prime} \rightarrow \infty$, it follows that $\eta^{S} \rightarrow 0$ for $\Phi[1-t] \rightarrow \infty$, hence $\frac{\partial \eta^{S}}{\partial \Phi[1-t]}<0$ over some interval for the after-tax real wage.

${ }^{21}$ Assuming that for $z>1$ there exist a value of the after-tax real wage for which $\frac{S}{S_{\Phi(1-t)}} \frac{\partial \eta^{S}}{\partial \Phi[1-t]}+\eta^{S}=0$ and that $\frac{S}{S_{\Phi(1-t)}} \frac{\partial \eta^{S}}{\partial \Phi[1-t]}$ decreases in $\Phi[1-t]$.
} 
a real revenue of $\widehat{T}$ should be collected and be distributed as transfers can be formulated as the following Lagrange problem

$$
\max _{t} \Upsilon=U(\Phi S+V(1-S), 0)+\mu[t \Phi S-\widehat{T}],
$$

where $\mu$ is the Lagrange multiplier measuring the effects on utility of changing the revenue requirement. The first order condition reads

$$
U_{B} B_{t}+\mu\left[R+t R_{t}\right]=0
$$

and the marginal costs of public funds measured in monetary equivalents are

$$
M C P F \equiv \frac{\mu}{U_{B}}=-\frac{B_{t}}{R+t R_{t}}
$$

where $R$ denotes real income generated in the private sector, i.e. $R \equiv w \phi(\mathbf{Q}) S(\Phi[1-t])$. The $M C P F$ thus measures how much real income private households lose if the real income going to the public sector increases by one unit.

Measures of marginal costs of public funds are often used as both a metric of tax distortions and inputs in assessing optimal policies (see also below). It is therefore interesting to see how integration affects the marginal costs of public funds. We consider the direct effect of integration holding the tax rate constant. Obviously the optimal policy response may be to change the tax rate, and we return to this question below. Since there are policy spill-overs it follows that the effect of integration in general differ depending on whether the marginal costs are assessed in cooperative or non-cooperative equilibrium. In the latter scenario, policy makers take into account that fiscal policy affects the relative wage, and thus competitiveness and terms of trade. Before addressing these questions, it is worth noting that in the symmetric non-cooperative case the costs of increasing the revenue constraint in both countries equals those of the cooperative case.

Considering first the marginal costs of public funds in the cooperative case, we have

Proposition 9 Marginal costs of public funds and integration in the cooperative case:

We have that

$$
\left.M C P F\right|_{\text {coop }}=\frac{\frac{t}{S} \frac{\partial \widetilde{S}}{\partial t}}{1-\frac{t}{S} \frac{\partial \widetilde{S}}{\partial t}}=\frac{\frac{t}{1-t} \eta^{S}}{1-\frac{t}{1-t} \eta^{S}}
$$

Hence

$$
\operatorname{sign} \frac{\left.\partial M C P F\right|_{\text {coop }}}{\partial m}=\operatorname{sign}\left[\frac{\partial \eta^{S}}{\partial \Phi[1-t]}\right]
$$

Proof. In a cooperative equilibrium, we have

$$
\begin{aligned}
& B_{t}=t \Phi S_{t}=-t \Phi \frac{\partial \widetilde{S}}{\partial t} \\
& R_{t}=\Phi S_{t}=-\Phi \frac{\partial \widetilde{S}}{\partial t}
\end{aligned}
$$


implying that $\left.M C P F\right|_{\text {coop }}$ can be written

$$
\left.M C P F\right|_{\text {coop }}=\frac{\frac{t}{S} \frac{\partial \widetilde{S}}{\partial t}}{1-\frac{t}{S} \frac{\partial \widetilde{S}}{\partial t}}=\frac{\frac{t}{1-t} \eta^{S}}{1-\frac{t}{1-t} \eta^{S}}
$$

It follows that

$$
\frac{\left.\partial M C P F\right|_{\text {coop }}}{\partial m}=\frac{\frac{t}{1-t}}{\left[1-\frac{t}{1-t} \eta^{S}\right]^{2}} \frac{\partial \eta^{S}}{\partial \Phi[1-t]} \frac{\partial \Phi[1-t]}{\partial m}
$$

In the cooperative case marginal costs of public funds increase (decrease) if further integration via the implied real wage increase drives the labour market to a more (less) elastic part of the labour supply curve. The fact that the effects depends only on the properties of the labour supply relation follows from the observation made in section 3 , that only the margin between consumption and leisure is relevant for tax distortions if the two countries are in a symmetric position which by definition is the case in the cooperative case.

It is an implication that $\left.M C P F\right|_{\text {coop }}$ is unaffected by integration if the labour supply elasticity is constant

Corollary 10 Given a constant labour supply elasticity $\left.M C P F\right|_{\text {coop }}$ is invariant to integration Proof. Set $\frac{\partial \eta^{S}}{\partial \Phi[1-t]}=0$ in Proposition 9

In the non-cooperative case where policy makers take into account that fiscal policy affects the relative wage, we have

$$
\begin{aligned}
\frac{\left.\partial M C P F\right|_{\text {non-coop }}}{\partial m} & =-\frac{B_{t m}\left[R+t R_{t}\right]-B_{t}\left[R_{m}+t R_{t m}\right]}{\left[R+t R_{t}\right]^{2}} \\
& =-\frac{B_{t}}{R+t R_{t}}\left[\frac{B_{t m}}{B_{t}}-\frac{R_{m}+t R_{t m}}{R+t R_{t}}\right]
\end{aligned}
$$

or in terms of elasticities

$$
\eta_{\left.M C P F\right|_{n o n-c o o p}, m}=-\lambda \eta_{R, m}+(\lambda-1) \eta_{R_{t}, m}+\eta_{B_{t}, m}
$$

where $\eta_{y, x}$ denotes the elasticity of $y$ wrt. $x$, and $\lambda \equiv \frac{R}{R+t R_{t}}=\frac{1}{\eta_{t R, t}}>1$.

The direction in which $\left.M C P F\right|_{\text {non-coop }}$ changes when product markets become more integrated features three effects ${ }^{22}$. Two of these are related to the tax base $(R)$

i) (tax base). We have that $\eta_{R, m}>0$, i.e. tighter integration increases real income generated in the private sector, hence $-\lambda \eta_{R, m}<0$. This effect implies that $\left.M C P F\right|_{\text {non-coop }}$ tends to fall when trade frictions are lowered. The reason is a tax base effect from integration, namely that

\footnotetext{
${ }^{22}$ In our interpretation below, we consider the empirical relevant case with $\left.M C P F\right|_{\text {non-coop }}>0, R_{t}<0$ and $B_{t}<0$. This will be the case for a sufficiently high revenue constraint $(\hat{T})$.
} 
the tax base for the income tax increases due to gains from trade, and this tends to lower the marginal costs of public funds. ${ }^{23}$

ii) (tax base sensitivity). $R_{t}$ measures how the tax rate affects the real income, and $\eta_{R_{t}, m}$ measures the responsiveness hereof to integration. If a given tax rate reduces the private real income more with more integration, we have $\eta_{R_{t}, m}>0$, implying that $\left.M C P F\right|_{\text {non-coop }}$ tends to increase with further integration (notice $\lambda>1$ ) and vice versa

iii) (private consumption bundle sensitivity). $B_{t}$ measures how the tax rate affects the private utility bundle, and $\eta_{B_{t}, m}$ measures the responsiveness hereof to integration. A higher tax rate reduces the private utility bundle $B_{t}<0$, but is this effect larger or smaller with a larger trade friction? If a given tax reduces the private utility bundle less with more integration $\eta_{B_{t}, m}<0$, implying that $\left.M C P F\right|_{\text {non-coop }}$ tends to decrease when markets are more integrated.

Note that the tax base effect (i) is unambiguously signed, while the latter two are ambiguously signed. Hence, it is ambiguous whether marginal costs of public funds are increasing or decreasing with further integration. The decomposition of the change in the marginal costs of public funds is interesting for several reasons. First, it shows that although there is no factor mobility, and thus no direct tax base mobility, there is an indirect effect on the tax base. The tax base grows due to gains from integration, and hence the indirect effect works in the opposite direction of the much debated direct mobility effect. Second, turning to tax distortions we find that there are separate effects via both real income $(R)$ and the private consumption bundle $(B)$. If taxes tend to lower both of these, and this effect becomes stronger with more integration, this tends to increase the marginal costs of public funds. This is the type of effect often highlighted in debates on how globalization affects the costs of taxation. The present analysis qualifies this debate in two important respects: i) it is not generally the case that tax distortions on real income and the private consumption bundle are reinforced by more integration, and ii) even if they are, the overall effect may still be a decrease in the marginal costs of public funds due to the tax base effect.

Turning to optimal policies (utilitarian policy makers), non-cooperative policies may be biased relative to cooperative policies. In policy debates, it is often presumed that a concern for competitiveness leads to a downward bias (undercutting or race to the bottom) in public policies. We now turn to a consideration of this issue.

${ }^{23}$ If we measure marginal costs of public funds in utility terms, i.e.

$$
m c p f=-U_{B} \frac{B_{t}}{R+t R_{t}}
$$

an additional term, namely $\frac{U_{B B}}{U_{B}} \eta_{B, z}>0$, would appear in the decomposition of the elasticity. Measuring in utility terms takes into account that the value of one monetary unit is not the same across equilibria. Intuitively, lower trade frictions increase the private utility bundle and thereby reduce marginal utility of the private bundle and thus the value of monetary units. This tends to reduce the marginal costs of public funds. Hence, we have chosen the more pessimistic measure in the analysis.

Note that the propositions above do not depend on which definition is used. 
Proposition 11 Evaluated for the same tax rate, the marginal costs of public funds are larger in the cooperative than in the non-cooperative case iff tax revenues in the two cases move in the same direction following a change in the tax rate. ${ }^{24}$

Proof. In the cooperative case, we have $w \equiv 1$ and thus $\frac{\partial w}{\partial t}=0$, implying

$$
\begin{aligned}
& M C P F \quad \mid \quad \text { coop }=-\frac{\left.B_{t}\right|_{\text {coop }}}{R+\left.t R_{t}\right|_{\text {coop }}}=-\frac{t \Phi S_{t}}{R+t \Phi S_{t}} \\
& M C P F \quad \mid{ }_{\text {non-coop }}=-\frac{\left.B_{t}\right|_{n o n-c o o p}}{R+\left.t R_{t}\right|_{\text {coop }}}=-\frac{t \Phi S_{t}+\left[t \Phi S_{w}+\Phi \Phi_{w} S\right] \frac{\partial w}{\partial t}}{R+t\left[\Phi S_{t}+\left[\Phi S_{w}^{s}+\Phi_{w} S\right] \frac{\partial w}{\partial t}\right]}
\end{aligned}
$$

Using (9) and that $S_{t}=-S_{\Phi[1-t]} \frac{\Phi}{\Phi_{w}} \frac{1}{1-t}$ (see (4)), we have

$$
\left.M C P F\right|_{\text {coop }}>\left.M C P F\right|_{\text {non-coop }} \Leftrightarrow \frac{\partial w}{\partial t}\left[R+\left.t R_{t}\right|_{\text {coop }}\right]\left[R+\left.t R_{t}\right|_{\text {non-coop }}\right]>0
$$

Thus, MCPF $\left.\right|_{\text {coop }}>\left.M C P F\right|_{\text {non-coop }}$ iff $\operatorname{sign}\left[R+\left.t R_{t}\right|_{\text {coop }}\right]=\operatorname{sign}\left[R+\left.t R_{t}\right|_{\text {non-coop }}\right]$. As tax revenues are given by $t R, R+t R_{t}$ is the derivative of tax revenues wrt. the tax rate.

Due to the positive terms of trade effect from raising taxes $\left(\frac{\partial w}{\partial t}>0\right)$, countries acting noncooperatively face lower marginal costs of public funds for a given tax rate ${ }^{25} 26$. This has important implications for optimal tax rates, since

Proposition 12 The optimal tax in the cooperate case is zero, while it is positive in the noncooperative case.

Proof. The first part follows directly from standard economic theory. The second part follows from noting either $\left.M C P F\right|_{n o n-c o o p, t=0}=-\frac{\Phi_{w}}{\Phi} \frac{\partial w}{\partial t}<0$ or $\left.U_{B} B_{t}\right|_{t=0}=\Phi_{w} S \frac{\partial w}{\partial t}>0$

This is a striking result since the case considered here is designed to focus on the distortionary effect $(\xi=1)$, and yet we find that the optimal tax rate is positive in the non-cooperative case. The intuition is that non-cooperative policy makers perceive that they by choosing a positive tax rate can turn the terms of trade to their advantage ${ }^{27}$ (a similar effect is found in the literature on optimal tariffs etc.). No such effect is present in the cooperative case, and therefore the non-cooperative tax rate exceeds the cooperative tax rate in a pure tax-transfer scheme. In a symmetric equilibrium, there are no improvements in the terms of trade, and thus from a social

\footnotetext{
${ }^{24}$ If the Laffer curves are single peaked, this corresponds to being on the same side of the curves.

${ }^{25}$ However, the marginal costs of a common increase in the revenue constraint are of course the same in the two scenarios.

${ }^{26}$ In the non-cooperative case, we consider a unilateral increase in the revenue constraint, i.e. an increase in $\hat{T}$ for a given $\hat{T}^{*}$.

${ }^{27}$ In fact, if $\frac{\Phi_{w}}{\Phi} \frac{\partial w}{\partial t}>1$, i.e. if the terms of trade effect is sufficiently strong $\left(\frac{\partial w}{\partial t}\right)$ or sufficiently important to consumption $\left(\frac{\Phi_{w}}{\Phi}\right)$, the government in the non-cooperative case has an incentive to collect taxes and destroy the resources (if redistribution is not possible).
} 
point of view, tax rates are too high in the non-cooperative case. This result complements the literature pointing to an upward bias in non-cooperative public policies due to a home bias in public consumption in models with exogenous specialization, cf. introduction. Here, we find a similar bias for transfers in a case with endogenous specialization and where the preferences of the public sector over domestic and foreign produced goods do not play a role.

\section{Optimal level of public consumption}

The determination of the optimal level of public consumption is more complicated since it involves the direct utility effects and the consequences of tax financing hereof, and therefore also in turn how these factors are affected by further integration. Does integration necessarily lead to a retrenchment of public sector activities? We consider this issue in two steps. First, we consider the cooperative outcome to clarify the basic mechanisms through which trade and integration affect the level of public sector activities. Next, we consider the non-cooperative case and compare it to the cooperative case to clarify the spill-over effects involved.

In the present set-up with a representative consumer, the relevant issue is the level of public service provision $(\xi=0)$, and we take the tax rate $(t)$ to be the policy instrument ${ }^{28}$. We assume a utilitarian social planner, and for $\xi=0$ we have that private and public consumption can written, respectively, as

$$
\begin{aligned}
& B(w, t, m)=\Phi(w, m)[1-t] S(w, t, m)+V(1-S(w, t, m)) \\
& G(w, t, m)=t S(w, t, m)
\end{aligned}
$$

\subsection{Optimal fiscal policies - the cooperative case}

In the cooperative case, $t=t^{*}$ and the relative wage is constant $(w=1)$, and the optimal tax rate is determined by the following conditions

$$
\begin{gathered}
-U_{B} B_{t}=U_{G} G_{t} \\
0>U_{B B} B_{t}^{2}+U_{B} B_{t t}+U_{B G} B_{t} G_{t}+U_{G B} G_{t} B_{t}+U_{G G} G_{t}^{2}+U_{G} G_{t t}
\end{gathered}
$$

where

$$
\begin{aligned}
& B_{t}=-\Phi S<0 \\
& G_{t}=S+t S_{t} \lesseqgtr 0
\end{aligned}
$$

The cost of raising taxes measured in terms of the private consumption bundle $B_{t}$ is unambiguously negative, while the effect of a change in the tax rate on public consumption $G_{t}$ is ambiguous due

\footnotetext{
${ }^{28}$ In the non-cooperative case redistribution could be optimal if marginal utility of public consumption is sufficiently low. We assume this is not the case.
} 
to a positive direct effect and a negative indirect effect (due to a reduction in private sector employment). The condition (14) is thus giving the Samuelson condition for the determination of the optimal level of public consumption as the marginal costs (the LHS of (14)) equal to the marginal benefits (the RHS of (14)).

To see how integration affects the optimal level of public consumption, it is useful to rewrite (14) in terms of the marginal costs of public funds. Using that the public sector budget constraint in equilibrium reads $G=t S$ and $R=\Phi S$, it follows that the marginal costs of public funds can be written

$$
M C P F=-\frac{B_{t}}{\Phi G_{t}}=\frac{S}{S+t S_{t}}
$$

and hence the condition determining optimal public consumption can be rewritten

$$
U_{G}=\Phi M C P F U_{B}
$$

This condition says that the optimal level of public consumption is determined where the marginal benefits of public consumption (the LHS of the expression) is equal to its marginal costs (the RHS of the expression) which is the product of the real cost of hiring an additional public employee times the marginal costs of raising this funds times the marginal utility of private consumption measuring the opportunity costs of giving up private consumption possibilities. Considering the effects of a change in integration it follows straightforwardly that

$$
\frac{\partial U_{G}}{\partial m}=\frac{\partial \Phi}{\partial m} M C P F U_{B}+\Phi \frac{\partial M C P F}{\partial m} U_{B}+\Phi M C P F \frac{\partial U_{B}}{\partial m}
$$

The right hand side of this expression gives how the marginal costs of public consumption is affected by integration. It includes the following three effects.

(i) a cost effect: $\frac{\partial \Phi}{\partial m}>0$, i.e. with more integration the real wage goes up, and therefore the cost of public employment goes up in real terms

(ii) a distortion effect: integration affects the $M C P F$, and if it increases, it makes the collection of tax revenue more costly and vice versa. In general, $\frac{\partial M C P F}{\partial m}$ is ambiguously signed, cf. above ${ }^{29}$.

(iii) a gains from trade effect: if the marginal utility of private consumption decreases due to integration, this tends to lower the costs of public consumption and vice versa. An increase in private consumption tends to work in the direction of lowering the marginal utility of the private consumption bundle.

Note that the expression above includes a Baumol-effect released by integration. Product market integration leads to productivity increases for private goods since production becomes better aligned to comparative advantages (a basic reason for gains from trade). This is the basic source of the increase in the real wage. However, productivity in production of public services is unchanged $(=1)$, and therefore private goods become relatively cheaper to public consumption. This is captured in the cost effect in the expression above.

\footnotetext{
${ }^{29}$ We have that $M C P F^{\text {Public consumption }}=M C P F^{\text {Transfers }}+1$.
} 
If preferences are separable in private and public consumption, marginal utility of private (public) consumption goes down if private (public) consumption goes up. Hence, under this assumption the level effect on public consumption follows immediately from (16). In the general case with non-separable preferences, the effects are slightly more complicated due to cross effects in marginal utilities. ${ }^{30}$.

In the preceding, we have characterized the optimal policy in terms of public consumption, but it can also be expressed in terms of the optimal tax rate. However, this is slightly more complicated. The reason is that since the public sector budget constraint implies $S^{g}=\frac{t}{1-t} S^{p}$, it follows that an increase in public consumption $\left(=S^{g}\right)$ is possible without a higher tax rate. The reason is that integration increases the tax base, which in turn leads to a revenue increase for a given tax rate. However, for public consumption relative to private consumption $\left(\frac{S^{g}}{\Phi S^{p}}\right)$ to increase requires an increase in the tax rate. ${ }^{31}$

It follows that the effects of product market integration can not be readily inferred from the change in public consumption. Considering the tax response, we have from (14) that

$$
\frac{\partial t}{\partial m}=-\frac{U_{B B} B_{m} B_{t}+U_{B} B_{t m}+U_{B G} B_{t} G_{m}+U_{G G} G_{m} G_{t}+U_{G} G_{t m}+U_{G B} G_{t} B_{m}}{U_{B B} B_{t}^{2}+U_{B} B_{t t}+H_{G G} G_{t}^{2}+H_{G} G_{t t}}
$$

and the second order condition (15) implies

$$
\begin{aligned}
\operatorname{sign} \frac{\partial t}{\partial m} & =-\operatorname{sign}\left[\eta_{U_{B}, B} \eta_{B, m}+\eta_{B_{t}, m}-\eta_{U_{G}, G} \eta_{G, m}-\eta_{G_{t}, m}-\eta_{U_{G}, B} \eta_{B, m}+\eta_{U_{B}, G} \eta_{G, m}\right] \\
& =-\operatorname{sign}\left[\left[\eta_{U_{B}, B}-\eta_{U_{G}, B}\right] \eta_{B, m}+\left[\eta_{U_{B}, G}-\eta_{U_{G}, G}\right] \eta_{G, m}+\eta_{B_{t}, m}-\eta_{G_{t}, m}\right]
\end{aligned}
$$

This expression ${ }^{32}$ involves both gains from trade effects, and distortions ${ }^{33}$.

$$
\begin{aligned}
& { }^{{ }^{30} \text { Allowing for non-separability, we have }} \\
& {\left[\begin{array}{rl}
{\left[U_{G G} \frac{\partial G}{\partial m}+U_{G B} \frac{\partial B}{\partial m}\right]} & =\frac{\partial \Phi}{\partial m} M C P F U_{B}+\Phi \frac{\partial M C P F}{\partial m} U_{B}+\Phi M C P F\left[U_{B G} \frac{\partial G}{\partial m}+U_{B B} \frac{\partial B}{\partial m}\right] \\
\frac{\partial G}{\partial m} & =\left[U_{G G}-\Phi M C P F U_{B G}\right]^{-1}\left[\frac{\partial \Phi}{\partial m} M C P F U_{B}+\Phi \frac{\partial M C P F}{\partial m} U_{B}+\left[\Phi M C P F U_{B B}-U_{G B}\right] \frac{\partial B}{\partial m}\right]
\end{array}\right.}
\end{aligned}
$$

For $U_{G G}-\Phi M C P F U_{B G}<0, \Phi M C P F U_{B B}-U_{G B}<0$, we have the same qualitative predictions as with separability.

${ }^{31}$ In fact, as $\Phi_{m}>0$ the tax rate must increase just to keep $\frac{S^{g}}{\Phi S^{p}}$ constant when there is more integration $(m$ increases), cf. the Baumol-effect mentioned above. However, the tax rate is the only variable affecting the ratio of public to private expenditures.

${ }^{32}$ Note this is a generalization of the expression in Andersen (2006) for exogenous production/specialization.

${ }^{33}$ In the special case with exogenous labour supply, we have

$$
\operatorname{sign} \frac{\partial t}{\partial m}=-\operatorname{sign}\left[\eta_{U_{B}, B}+1\right]
$$

An increase in $m$ corresponds to higher productivity in the private sector. First, the $\eta_{U_{B}, B}$ term captures that higher productivity implies high consumption and low marginal utility. This calls for a higher tax rate. Secondly, high productivity also implies that private consumption is more responsive to public consumption, which calls for a low tax (this is captured by the second term). 
First, the term $\eta_{B, m}>0$ captures the increase in the private consumption bundle accruing with more integration. The direction in which this affects the optimal tax rate depends on whether it reduces the marginal benefit of the private consumption bundle or public consumption the most. If $\eta_{U_{B}, B}-\eta_{U_{G}, B}<0$ (note $\eta_{U_{B}, B}<0$ ), we have that the marginal utility of the private consumption bundle is reduced the most, and this works to increase the tax rate, and vice versa when $\eta_{U_{B}, B}-\eta_{U_{G}, B}>0$.

Second, the term $\eta_{G, m}>0$ captures how integration implies a gain in public consumption via a larger tax base. The effect of this depends on how the marginal utility of the private consumption bundle is affected relative to the marginal utility of public consumption. If $\eta_{U_{B}, G}-\eta_{U_{G}, G}<0$ (note $\eta_{U_{G}, G}<0$ ), the marginal utility of the private consumption bundle falls by more than the marginal utility of public consumption, and this tends to work in the direction of increasing the tax rate, and vice versa for $\eta_{U_{B}, G}-\eta_{U_{G}, G}>0$.

Finally, there is a distortion effect which has two elements, namely, how integration influences how much a given tax rate reduces the private consumption bundle $\left(B_{t}\right)$, and how it influences how much a given tax influences public consumption. We have that $\eta_{B_{t}, m}>0$, and this effect therefore works in the direction of lowering the tax rate, while $\eta_{G_{t}, m}$ is ambiguously signed.

\subsection{Optimal fiscal policies: Non-cooperative vs. cooperative policies}

We consider possible spill-over effects in fiscal policy by comparing the non-cooperative and cooperative policy choices. The cooperative solution is already given in the previous sub-section, cf. (14). The choice of the tax rate in the non-cooperative case is determined by the first order condition

$$
-U_{B} B_{t}-\left[U_{B} B_{w}+U_{G} G_{w}\right] \frac{\partial w}{\partial t}=U_{G} G_{t}
$$

where the marginal effects of a change in the relative wage $(w)$ on private and public consumption, respectively, are given by

$$
\begin{aligned}
B_{w} & =\Phi_{w}(1-t) S>0 \\
G_{w} & =t S_{w}>0
\end{aligned}
$$

Proposition 13 The optimal tax rate in the non-cooperative case is larger than the optimal tax rate in the cooperative case.

Proof. Comparing the non-cooperative case (17) to the cooperative case (14), we have that the difference is caused by the term

$$
-\left[U_{B} B_{w}+U_{G} G_{w}\right] \frac{\partial w}{\partial t}<0
$$

The term captures the effect a change in the tax rate has on the relative wage. It follows that the marginal costs of public activities are smaller in the non-cooperative than in the cooperative 
case. Consequently, the optimal level of public activity is larger in the non-cooperative than in the cooperative case.

The expansionary bias arising in the non-cooperative case is caused by policy makers perceiving that they can turn the terms of trade or the relative wage to their advantage. ${ }^{34}$ The advantage arises both from the effect of the terms of trade increase on real income, and the fact that a higher real wage expands labour supply and thus increases public consumption. Of course this is not possible in the symmetric equilibrium, and therefore public consumption is too high in the non-cooperative case.

Interestingly, we find that even though the production structure is endogenous and a fiscal expansion implies a deterioration of wage competitiveness, an expansionary bias appears in noncooperative policies. The reason is that the bias is not related to whether a fiscal expansion leads to an expanded or contracted level of activity but to the perceived gain attained via an improvement in the terms of trade. This generalizes a result well known from models with exogenous specialization, cf. the introduction.

Finally, since this finding is controversial it may be questioned whether this result depends on the assumed utilitarian objective function. In appendix $C$, we show that the same qualitative result holds if fiscal policy aims at maximizing e.g. real income or total employment.

\section{Concluding remarks}

In popular debates, it is often taken for granted that globalization makes income taxation more distortionary. The argument is that taxation deteriorates competitiveness and the importance of competitiveness increases with globalization. A race to the bottom in income taxation has also been suggested along these lines. These views are not confirmed in the model above, where taxation deteriorates competitiveness, globalization reduces trade frictions, and trade and production structures are endogenous.

The present analysis has shown that the effects of globalization in the form of product market integration for both the effects of fiscal policies and optimal policies are far from obvious. First, integration may or may not release effects tending to make taxation more distortionary. Second, even if taxes become more distortionary, we find that the gains from trade following integration work in the direction of lowering marginal costs of public funds. Accordingly, one can not generally conclude that income taxation would distort employment more with further product market integration, neither that the marginal costs of public funds go up, nor that optimal policies involve

\footnotetext{
${ }^{34}$ Even if $U_{G}=0$ optimal public consumption may be positive. In fact, if $\frac{\Phi_{w}}{\Phi} \frac{\partial w}{\partial t}>1$, i.e. if the terms of trade effect is sufficiently strong $\left(\frac{\partial w}{\partial t}\right)$ or sufficiently important to consumption $\left(\frac{\Phi_{w}}{\Phi}\right)$, the government in the non-cooperative case has an incentive to collect taxes and spend the money on useless public consumption (if redistribution is not possible).
} 
a retrenchment.

It is a robust finding of models with an exogenous production and specialization structure across countries that non-cooperative fiscal policies tend to have an expansionary bias. That is, fiscal policy is more expansive in the non-cooperative than in the cooperative case. We have shown that this insight generalizes to the case where the production/specialization structure is endogenous. Somewhat provocative, one might conclude from this analysis that the fear of retrenchment in the public sector due to increased tax competition might as well be replaced with a fear of too large and expanding public sectors. That said, we must stress that the representative agent framework applied does not take distributional consequences into account. Gains from increased trade are unevenly distributed, calling for more redistribution and thus an expanding public sector. Further, we have not taken mobility of production factors into account.

In the present paper, public sector activities have been modelled in a traditional way including a standard tax-transfer scheme and tax financed public consumption. While capturing basic effects, it also leaves out important aspects on the interaction between private and public sector activities. In particular since the model predicts a standard trade-off between the extent of public sector activities and distortions. The potential source of interactions between private and public sector activities most relevant in the present context runs via productivity (relative productivity is the driver of the Ricardian trade model). Two contrasting views are that public sector activities and distortions may be detrimental to innovation and therefore lead to lower productivity growth, or that public sector activities may increase productivity growth via investment in e.g. human capital and infrastructure. Another important aspect not addressed this paper is the question of inequality. Gains from trade are often distributed very unevenly, implying that demand for redistribution increases with product market integration. It is an interesting issue for further research to address these issues.

\section{Appendix A: Generalization of the private utility bundle}

A more general formulation of the private utility bundle is

$$
B=\Psi(C, F)
$$

where leisure $F=1-L$ and $\Psi$ is a two times continuously differentiable function ${ }^{35}$. The first order condition determining labour supply reads

$$
\Upsilon=\Psi_{C}\left(\phi(\mathbf{Q}) I, 1-L^{s}\right)[1-t] W \phi(\mathbf{Q})-\Psi_{F}\left(\phi(\mathbf{Q}) I, 1-L^{s}\right)=0
$$

and the second order condition reads

$$
\begin{aligned}
\Upsilon_{L} & =\Psi_{C C}[[1-t] W \phi(\mathbf{Q})]^{2}+\Psi_{F F}-\Psi_{C F}[1-t] W \phi(\mathbf{Q})-\Psi_{F C}[1-t] W \phi(\mathbf{Q}) \\
& =\Psi_{C C}[[1-t] W \phi(\mathbf{Q})]^{2}+\Psi_{F F}-2 \Psi_{F C}[1-t] W \phi(\mathbf{Q})<0
\end{aligned}
$$

\footnotetext{
${ }^{35} \Psi(C, F)$ is assumed to have the usual properties: $\Psi_{C}>0, \Psi_{F}>0, \Psi_{C C}<0$ and $\Psi_{F F}<0$
} 
Using the public budget $L^{p}=[1-[1-\xi] t] L$ and $\phi(\mathbf{Q}) I=W \phi(\mathbf{Q}) L^{p}$. Insert into the first order condition to get

$$
\hat{\Upsilon}=\Psi_{C}\left(W \phi(\mathbf{Q}) L^{s p}, 1-\frac{L^{s p}}{1-[1-\xi] t}\right)[1-t] W \phi(\mathbf{Q})-\Psi_{F}\left(W \phi(\mathbf{Q}) L^{s p}, 1-\frac{L^{s p}}{1-[1-\xi] t}\right)=0
$$

implicitly defining the aggregate labour supply function for the private sector. From the first order condition (18), we have

$$
\begin{aligned}
\frac{\partial L^{s p}}{\partial t} & =-\frac{\hat{\Upsilon}_{t}}{\hat{\Upsilon}_{L^{s p}}} \\
\frac{\partial L^{s p}}{\partial W \phi(\mathbf{Q})} & =-\frac{\hat{\Upsilon}_{W \phi(\mathbf{Q})}}{\hat{\Upsilon}_{L^{s p}}}
\end{aligned}
$$

where

$$
\begin{aligned}
\hat{\Upsilon}_{L^{s p}} & =\frac{\Upsilon_{L}}{1-[1-\xi] t}+\frac{\xi t W \phi(\mathbf{Q})}{1-[1-\xi] t}\left[[1-t] W \phi(\mathbf{Q}) \Psi_{C C}-\Psi_{F C}\right] \gtreqless 0 \\
\hat{\Upsilon}_{t} & =-\Psi_{C} W \phi(\mathbf{Q})-\Psi_{C F}[1-t] W \phi(\mathbf{Q}) \frac{L^{s p}[1-\xi]}{[1-[1-\xi] t]^{2}}+\Psi_{F F} \frac{L^{s p}[1-\xi]}{[1-[1-\xi] t]^{2}} \gtreqless 0 \\
\hat{\Upsilon}_{W \phi(\mathbf{Q})} & =\Psi_{C}[1-t]+\Psi_{C C} L^{s p}[1-t] W \phi(\mathbf{Q})-\Psi_{F C} L^{s p} \\
& =\Psi_{C}[1-t]\left[1+\eta_{\Psi_{C}, C}\right]-\Psi_{F C} L^{s p} \gtreqless 0
\end{aligned}
$$

The effects of the real wage and the tax rate on aggregate labour supply for the private sector are in general ambiguous. However, a sufficient condition for aggregate labour supply for the private sector to be decreasing in the tax rate is that consumption is not a substitute for leisure $\left(\Psi_{F C} \geq 0\right)$ as

$$
\Psi_{F C} \geq 0 \Rightarrow \hat{\Upsilon}_{L^{s p}}<0, \hat{\Upsilon}_{t}<0 \Rightarrow \frac{d L^{s p}}{d t}=L_{t}^{s p}=-\frac{\hat{\Upsilon}_{t}}{\hat{\Upsilon}_{L^{s p}}}<0
$$

\section{Appendix B: The equilibrium allocation and the relative wage}

We show that the equilibrium allocation can be characterized in terms of the relative wage $w \equiv \frac{W}{W^{*}}$.

\section{Market equilibria}

The equilibrium conditions for commodities and labour are

$$
\begin{aligned}
C_{i}+m C_{i}^{*} & =Y_{i} \text { for } i>i^{E}, \\
C_{i} & =Y_{i} \text { for } i^{H} \leq i \leq i^{E} \\
L^{d} & =L^{s}
\end{aligned}
$$


As noted in section 2, public employment is proportional to private employment. The labour market equilibrium condition is in the following stated in terms of demand for and supply of labour to the private sector.

\section{Labour demand}

Labour demand in the private sector can be written

$$
\begin{aligned}
L^{p} & =\int_{i^{H}}^{1} \frac{1}{A_{i}} C_{i} d i+\int_{i^{E}}^{1} \frac{z}{A_{i}} C_{i}^{*} d i \\
& =\int_{i^{H}}^{1} \frac{1}{A_{i}} \frac{e_{i}(\mathbf{Q}) I}{Q_{i}} d i+\int_{i^{E}}^{1} \frac{z}{A_{i}} \frac{e_{i}^{*}\left(\mathbf{Q}^{*}\right) I^{*}}{Q_{i}^{*}} d i
\end{aligned}
$$

The first part on the RHS is labour demand generated by supplying goods to the domestic market, and the second part is the labour demand generated by supplying to the foreign market (export). Insert that prices are given by marginal costs and private income is given by labour income in the private sector to obtain

$$
L^{p}=N^{H}\left(\mathbf{Q}, i^{H}\right) L^{p}+\frac{1}{w} N^{* M}\left(\mathbf{Q}, i^{G}\right) L^{* p}
$$

where

$$
\begin{aligned}
N^{H}\left(\mathbf{Q}, i^{H}\right) & \equiv \int_{i^{H}}^{1} e_{i}(\mathbf{Q}) d i \\
N^{* M}\left(\mathbf{Q}, i^{G}\right) & \equiv \int_{i^{E}}^{1} e_{i}^{*}\left(\mathbf{Q}^{*}\right) d i
\end{aligned}
$$

Note that $N^{H}\left(\mathbf{Q}, i^{H}\right)$ is the total share of income spent by domestic households on domestic commodities $\left(1=N^{H}\left(\mathbf{Q}, i^{H}\right)+N^{M}\left(\mathbf{Q}, i^{H}\right)\right)$, and $N^{* M}\left(\mathbf{Q}^{*}, i^{G}\right)$ is the share foreign households spend on domestic commodities. The latter can be interpreted as the trade share ${ }^{36}$. Exploiting that expenditure shares are homogeneous of degree zero, i.e. $e_{i}(\mathbf{Q})=e_{i}\left(\frac{1}{W} \mathbf{Q}\right)$ and $e_{i}^{*}\left(\mathbf{Q}^{*}\right)=e_{i}^{*}\left(\frac{1}{W} \mathbf{Q}^{*}\right)$, we have

$$
\begin{aligned}
N^{H}\left(\frac{\mathbf{Q}}{W}, i^{H}\right) & =\int_{i^{H}}^{1} e_{i}\left(\frac{\mathbf{Q}}{W}\right) d i=N^{H}\left(\mathbf{Q}, i^{H}\right) \\
N^{* M}\left(\frac{\mathbf{Q}^{*}}{W}, i^{E}\right) & =\int_{i^{E}}^{1} e_{i}^{*}\left(\frac{\mathbf{Q}^{*}}{W}\right) d i=N^{* M}\left(\mathbf{Q}, i^{E}\right)
\end{aligned}
$$

Consumer prices relative to wages are given $\operatorname{as}^{37}$

$$
\begin{array}{cc}
\frac{Q_{i}}{W}=z A_{i}^{*-1} \frac{W^{*}}{W}=\left[\frac{w}{z} A_{i}^{*}\right]^{-1} & \text { for } i<i^{H} \\
\frac{Q_{i}}{W}=A_{i}^{-1} & \text { for } i \geq i^{H}
\end{array}
$$

\footnotetext{
${ }^{36}$ The share is measured relative to total private income $I$ which in equilibrium equals the wage income generated in the private sector. Hence, the trade share is the "private" sector trade share, rather than the often used trade share defined relative to GDP.

${ }^{37}$ Observe that $z A_{i}^{*-1} \frac{W^{*}}{W}=A_{i}^{-1}$ for $i=i^{H}$, which implies that a marginal change affecting $i^{H}$ would not affect $\frac{\mathbf{Q}}{W}$.
} 
As consumer prices relative to the wage can be written as functions of the relative wage and the trade friction $(z)$ as $i^{H}\left(\frac{w}{z}=a_{i^{H}}\right)$, we have

$$
N^{H}\left(\frac{\mathbf{Q}}{W}, i^{H}\right) \equiv \psi^{H}(w, m)
$$

As $w$ and $z$ always enter as $\frac{w}{z}$, it follows that

$$
\operatorname{sign} \frac{\partial \psi^{H}}{\partial w}=\operatorname{sign} \frac{\partial \psi^{H}}{\partial m}
$$

Hence, if more integration $(m)$ reduces the share of income spent by domestic consumers on domestic products, so does a higher relative wage, and vice versa. Similarly, we have for the foreign consumers

$$
N^{* M}\left(\frac{\mathbf{Q}^{*}}{W}, i^{E}\right) \equiv \psi^{* M}(w, m)
$$

where

$$
\operatorname{sign} \frac{\partial \psi^{* M}}{\partial w}=\operatorname{sign}\left[-\frac{\partial \psi^{* M}}{\partial m}\right]
$$

If an increase in $m$ lowers this share, then an increase in the relative wage will increase this share.

The employment relation (22) can now in a more compact way be written

$$
\psi^{M}(w, m) L^{p} w=\psi^{* M}(w, m) L^{p *}
$$

where $\psi^{M}(w, m)=1-\psi^{H}(w, m)$. Note that $\psi^{M}(1, m)=\psi^{* M}(1, m)$.

\section{Real wage}

Using homogeneity of the $\phi$-function and the relation between prices and wages given in (24), the real wage can be written

$$
W \phi(\mathbf{Q})=\phi\left(\frac{1}{W} \mathbf{Q}\right) \equiv \Phi(w, m)
$$

$>$ From (24) and homogeneity, it follows that the real wage is increasing in the relative wage and decreasing in trade frictions, i.e.

$$
\frac{\partial \Phi(w, m)}{\partial w}>0, \frac{\partial \Phi(w, m)}{\partial m}>0
$$

\section{Product market equilibrium}

For any commodity $i$, activity is demand determined due to the constant returns to scale assumption. Product demand for a given commodity $i$ is in equilibrium

$$
\begin{aligned}
& D_{i}=\frac{e_{i}(\mathbf{Q}) I}{Q_{i}} \quad \text { for } i^{H}<i<i^{E} \\
& D_{i}=\frac{e_{i}(\mathbf{Q}) I}{Q_{i}}+\frac{z e_{i}^{*}\left(\mathbf{Q}^{*}\right) I^{*}}{Q_{i}^{*}} \quad \text { for } i \geq i^{E}
\end{aligned}
$$


and this gives rise to a needed amount of labour $\frac{1}{A_{i}} D_{i}$. Hence, when aggregating labour demand for the specific commodities into the aggregate labour demand relation (22) and ensuring equality between labour demand and supply, it follows that the overall employment level is consistent with having the available labour needed for production of all goods demanded at the equilibrium relative wage. In short, when the labour market is in equilibrium for a given relative wage, it follows that all product markets by construction are also in equilibrium.

\section{Labour market equilibrium}

Consider first labour supply (4). Using that public labour demand $L^{g}=(1-\xi) t L$ and $\phi(\mathbf{Q}) W=\Phi(w, m)$, we have that labour supply to the private sector can be written as

$$
\begin{aligned}
S^{p} & =[1-[1-\xi] t] S(\Phi(w, m)[1-t]) \\
& \equiv S^{p}(w, \xi, t, m)
\end{aligned}
$$

Quasilinearity of the private consumption bundle ensures that labour supply is increasing in the relative wage and decreasing in both the trade friction and the tax rate, i.e.

$$
\frac{\partial S^{p}(w, \xi, t, m)}{\partial w}>0, \frac{\partial S^{p}(w, \xi, t, m)}{\partial m}>0, \frac{\partial S^{p}(w, \xi, t, m)}{\partial t}<0
$$

Hence, the equilibrium condition can by use of (25) be written

$$
\psi^{M}(w, m) S^{p}(w, \xi, t, m) w=\psi^{* M}(w, m) S^{p *}\left(w, \xi^{*}, t^{*}, m\right)
$$

implying that the relative wage can be written

$$
w=\omega\left(t, \xi, t^{*}, \xi^{*}, m\right)
$$

For a given relative wage, it follows that the trade structure is determined (via $i^{H}$ and $i^{E}$ ) and the level of production of all goods $i$ follows from $(27,28)$, the real wage follows from (26) and employment follows from (22).

\section{Appendix C: Non-cooperative policy bias and alternative objective functions}

The results in section 6 were derived assuming that the policy maker is utilitarian. In the following, we consider alternative political objective functions to show that the main result on the bias in non-cooperative policies does not depend on the particular objective function.

\section{Real income}

Real income is given as

$$
\Phi(w, m) S^{p}(w, \xi, t, m)
$$


The first order condition for the optimal tax rate in the non-cooperative case reads

$$
\left[\Phi_{w} S^{p}+\Phi S_{w}^{p}\right] \frac{\partial w}{\partial t}+\Phi S_{t}^{p}=0
$$

Hence, the bias depends on the relative wage effect, and with the same sign as in the case considered in the main body of the paper.

\section{Employment}

Assume that the objective is to maximize total employment, i.e.

$$
\frac{1}{1-t} S^{p}(w, \xi, t, m)
$$

we have that the foc reads

$$
\frac{1}{[1-t]^{2}} S^{p}+\frac{1}{1-t} S_{t}^{p}+\frac{1}{1-t} S_{w}^{p} \frac{\partial w}{\partial t}=0
$$

Hence, the bias depends on the relative wage effect, and with the same sign as in the case considered in the main body of the paper.

\section{References}

Andersen, T.M., 2006, The Public Sector and International Integration, Economics Letters, 2006, 93, 202-09.

Andersen, T.M., 2007, Fiscal policy coordination and international trade, Economica, (to appear).

Andersen, T.M., B.S. Rasmussen, and J.R. Sørensen, 1996, Optimal Fiscal Policies in Open Economies with Labour Market Distortions, Journal of Public Economics, 63, 103-117.

Baxter, M., and R. King, 1993, Fiscal Policy in General Equilibrium, American Economic Review, 83, 159-192.

Bergin, P.R, and R. Glick, 2003, Endogenous Nontradeability and Macroeconomic Implications, NBER Working Paper 9739.

Bernard, A.B., and J. Bradford Jensen, "Exceptional Exporter Performance: Cause, Effect or Both?" Journal of International Economics 47 (1999):1-25.Bernard, A.B., and J. Bradford Jensen, "Exporting and Productivity: The Importance of Reallocation," Working Paper (2001).

Bernard, A.B., J. Eaton, J. Bradford Jensen, and S. Kortum, "Plants and Productivity in International Trade," American Economic Review 93 (2003):1268-1290.

Bernhard, A.B, J.B. Jensen and P.K. Schott, "Falling Trade Costs, Heterogenous Firms, and Industry Dynamics," Working Paper (2004). 
Chari, V.V., and P.J. Kehoe, 1990, International coordination of fiscal policy in limiting economies, Journal of Political Economy, 98, 617-636.

Cooper, R., 1985, Economic Interdependence and Coordination of Economic Policies, in Jones, R.W, and P B. Kenen (eds.), Handbook of International Economics, Vol II, North-Holland (Amsterdam).

Devereux, M.B., 1991, The terms of trade and the international coordination of fiscal policy, Economic Inquiry, 29, 720-736.

Dornbusch, R., Fischer, S., and P.A. Samuelson, 1977, Comparative Advantage, Trade and Payments in a Ricardian Model with a Continuum of Goods, American Economic Review, 67, 823-839.

Eaton, J., and S. Kortum, 2002, Technology, geography and trade, Econometrica, 70, 1741-1779.

Helpman, E., M. Melitz and S. Yeaple, "Exports vs FDI with Heterogeneous Firms," American Economic Review, 94, 1 (2004)

Kleven, H.J. and C.T. Kreiner, 2006, "The Marginal Costs of Public Funds: Hours of Work versus Labour Force Participation, CEPR DP no. 5594

Melitz, M.J., 2002, The Impact of Trade on Intra-Industrial Reallocations and Aggregate Industry Productivity, NBER Working Paper 8881.

Razin, A. and E. Sadka, 2005, The decline of the welfare state - demography and globalization, CESifo Book Series, MIT Press (Cambridge).

Tanzi, V., 2000, Globalization and the future of social protection, IMF working paper WP/00/12

Turnovsky, S.J., 1988, Coordination of optimal taxation in a two-country equilibrium model, Journal of International Economics.

van der Ploeg, R., 1987, Coordination of Optimal Taxation in a Two-Country Equilibrium Model, Economics Letters, 24, 279-285.

van der Ploeg, R., 1988, International policy coordination in interdependent monetary economies, Journal of International Economics, 25, 1-23. 


\section{CESifo Working Paper Series}

for full list see www.cesifo-group.org/wp

(address: Poschingerstr. 5, 81679 Munich, Germany, office@cesifo.de)

2104 Laszlo Goerke and Marco Runkel, Tax Evasion and Competition, September 2007

2105 Scott Alan Carson, Slave Prices, Geography and Insolation in $19^{\text {th }}$ Century AfricanAmerican Stature, September 2007

2106 Wolfram F. Richter, Efficient Tax Policy Ranks Education Higher than Saving, October 2007

2107 Jarko Fidrmuc and Roman Horváth, Volatility of Exchange Rates in Selected New EU Members: Evidence from Daily Data, October 2007

2108 Torben M. Andersen and Michael Svarer, Flexicurity - Labour Market Performance in Denmark, October 2007

2109 Jonathan P. Thomas and Tim Worrall, Limited Commitment Models of the Labor Market, October 2007

2110 Carlos Pestana Barros, Guglielmo Maria Caporale and Luis A. Gil-Alana, Identification of Segments of European Banks with a Latent Class Frontier Model, October 2007

2111 Felicitas Nowak-Lehmann D., Sebastian Vollmer and Immaculada Martínez-Zarzoso, Competitiveness - A Comparison of China and Mexico, October 2007

2112 Mark Mink, Jan P.A.M. Jacobs and Jakob de Haan, Measuring Synchronicity and Comovement of Business Cycles with an Application to the Euro Area, October 2007

2113 Ossip Hühnerbein and Tobias Seidel, Intra-regional Tax Competition and Economic Geography, October 2007

2114 Christian Keuschnigg, Exports, Foreign Direct Investment and the Costs of Corporate Taxation, October 2007

2115 Werner Bönte, Oliver Falck and Stephan Heblich, Demography and Innovative Entrepreneurship, October 2007

2116 Katrin Assenmacher-Wesche and M. Hashem Pesaran, Assessing Forecast Uncertainties in a VECX Model for Switzerland: An Exercise in Forecast Combination across Models and Observation Windows, October 2007

2117 Ben Lockwood, Voting, Lobbying, and the Decentralization Theorem, October 2007

2118 Andrea Ichino, Guido Schwerdt, Rudolf Winter-Ebmer and Josef Zweimüller, Too Old to Work, too Young to Retire?, October 2007 
2119 Wolfgang Eggert, Tim Krieger and Volker Meier, Education, Unemployment and Migration, October 2007

2120 Stefan Napel and Mika Widgrén, The European Commission - Appointment, Preferences, and Institutional Relations, October 2007

2121 Bertil Holmlund and Martin Söderström, Estimating Income Responses to Tax Changes: A Dynamic Panel Data Approach, October 2007

2122 Doina Maria Radulescu, From Separate Accounting to Formula Apportionment: Analysis in a Dynamic Framework, October 2007

2123 Jelle Brouwer, Richard Paap and Jean-Marie Viaene, The Trade and FDI Effects of EMU Enlargement, October 2007

2124 Kurt R. Brekke, Luigi Siciliani and Odd Rune Straume, Competition and Waiting Times in Hospital Markets, October 2007

2125 Alexis Direr, Flexible Life Annuities, October 2007

2126 Johannes Becker and Clemens Fuest, Quality versus Quantity - The Composition Effect of Corporate Taxation on Foreign Direct Investment, October 2007

2127 Balázs Égert, Real Convergence, Price Level Convergence and Inflation Differentials in Europe, October 2007

2128 Marko Koethenbuerger, Revisiting the "Decentralization Theorem" - On the Role of Externalities, October 2007

2129 Axel Dreher, Silvia Marchesi and James Raymond Vreeland, The Politics of IMF Forecasts, October 2007

2130 Andreas Knabe and Ronnie Schöb, Subsidizing Extra Jobs: Promoting Employment by Taming the Unions, October 2007

2131 Michel Beine and Bertrand Candelon, Liberalization and Stock Market Co-Movement between Emerging Economies, October 2007

2132 Dieter M. Urban, FDI Technology Spillovers and Wages, October 2007

2133 Valentina Bosetti, Carlo Carraro, Emanuele Massetti and Massimo Tavoni, Optimal Energy Investment and R\&D Strategies to Stabilise Greenhouse Gas Atmospheric Concentrations, October 2007

2134 David-Jan Jansen and Jakob de Haan, The Importance of Being Vigilant: Has ECB Communication Influenced Euro Area Inflation Expectations?, October 2007

2135 Oliver Falck, Heavyweights - The Impact of Large Businesses on Productivity Growth, October 2007 
2136 Xavier Freixas and Bruno M. Parigi, Banking Regulation and Prompt Corrective Action, November 2007

2137 Jan K. Brueckner, Partial Fiscal Decentralization, November 2007

2138 Silvia Console Battilana, Uncovered Power: External Agenda Setting, Sophisticated Voting, and Transnational Lobbying, November 2007

2139 Alan J. Auerbach, Michael P. Devereux and Helen Simpson, Taxing Corporate Income, November 2007

2140 Lorenzo Cappellari, Paolo Ghinetti and Gilberto Turati, On Time and Money Donations, November 2007

2141 Roel Beetsma and Heikki Oksanen, Pension Systems, Ageing and the Stability and Growth Pact, November 2007

2142 Hikaru Ogawa and David E. Wildasin, Think Locally, Act Locally: Spillovers, Spillbacks, and Efficient Decentralized Policymaking, November 2007

2143 Alessandro Cigno, A Theoretical Analysis of the Effects of Legislation on Marriage, Fertility, Domestic Division of Labour, and the Education of Children, November 2007

2144 Kai A. Konrad, Mobile Tax Base as a Global Common, November 2007

2145 Ola Kvaløy and Trond E. Olsen, The Rise of Individual Performance Pay, November 2007

2146 Guglielmo Maria Caporale, Yannis Georgellis, Nicholas Tsitsianis and Ya Ping Yin, Income and Happiness across Europe: Do Reference Values Matter?, November 2007

2147 Dan Anderberg, Tax Credits, Income Support and Partnership Decisions, November 2007

2148 Andreas Irmen and Rainer Klump, Factor Substitution, Income Distribution, and Growth in a Generalized Neoclassical Model, November 2007

2149 Lorenz Blume, Jens Müller and Stefan Voigt, The Economic Effects of Direct Democracy - A First Global Assessment, November 2007

2150 Axel Dreher, Pierre-Guillaume Méon and Friedrich Schneider, The Devil is in the Shadow - Do Institutions Affect Income and Productivity or only Official Income and Official Productivity?, November 2007

2151 Valentina Bosetti, Carlo Carraro, Emanuele Massetti and Massimo Tavoni, International Energy R\&D Spillovers and the Economics of Greenhouse Gas Atmospheric Stabilization, November 2007

2152 Balázs Égert and Dubravko Mihaljek, Determinants of House Prices in Central and Eastern Europe, November 2007 
2153 Christa Hainz and Hendrik Hakenes, The Politician and his Banker, November 2007

2154 Josef Falkinger, Distribution and Use of Knowledge under the "Laws of the Web", December 2007

2155 Thorvaldur Gylfason and Eduard Hochreiter, Growing Apart? A Tale of Two Republics: Estonia and Georgia, December 2007

2156 Morris A. Davis and François Ortalo-Magné, Household Expenditures, Wages, Rents, December 2007

2157 Andreas Haufler and Christian Schulte, Merger Policy and Tax Competition, December 2007

2158 Marko Köthenbürger and Panu Poutvaara, Rent Taxation and its Intertemporal Welfare Effects in a Small Open Economy, December 2007

2159 Betsey Stevenson, Title IX and the Evolution of High School Sports, December 2007

2160 Stergios Skaperdas and Samarth Vaidya, Persuasion as a Contest, December 2007

2161 Morten Bennedsen and Christian Schultz, Arm’s Length Provision of Public Services, December 2007

2162 Bas Jacobs, Optimal Redistributive Tax and Education Policies in General Equilibrium, December 2007

2163 Christian Jaag, Christian Keuschnigg and Mirela Keuschnigg, Pension Reform, Retirement and Life-Cycle Unemployment, December 2007

2164 Dieter M. Urban, Terms of Trade, Catch-up, and Home Market Effect: The Example of Japan, December 2007

2165 Marcelo Resende and Rodrigo M. Zeidan, Lionel Robbins: A Methodological Reappraisal, December 2007

2166 Samuel Bentolila, Juan J. Dolado and Juan F. Jimeno, Does Immigration Affect the Phillips Curve? Some Evidence for Spain, December 2007

2167 Rainald Borck, Federalism, Fertility and Growth, December 2007

2168 Erkki Koskela and Jan König, Strategic Outsourcing, Profit Sharing and Equilibrium Unemployment, December 2007

2169 Egil Matsen and Øystein Thøgersen, Habit Formation, Strategic Extremism and Debt Policy, December 2007

2170 Torben M. Andersen and Allan Sørensen, Product Market Integration and Income Taxation: Distortions and Gains from Trade, December 2007 